\title{
From Passiveness to Activeness: the Transformation of China's Regulatory Measures on Weibo
}

\author{
Bei Guo \\ School of Journalism and Communication, \\ Shaanxi Normal University \\ Xi'an, Shaanxi Province, P.R.China \\ bei.guo@snnu.edu.cn
}

\begin{abstract}
Chinese internet censorship has attracted wide attention from all over the world. With the increasing importance of Weibo in the daily life of the Chinese people, it is necessary to explore how the Communist Party of China specifically responds to and regulates Weibo among other social media. This paper focuses on government Weibo in order to capture the Chinese government's evolving aims, strategies and tactics in regulating Weibo. In addition to the "hard" regulatory measures of censorship, more significantly, this paper highlights the new channels for active involvement of government in the regulation of Weibo, including the establishment of government Weibo accounts and the interaction with the public by this account. This proactive measure for using Weibo has a number of advantages, such as improving the government's transparency and strengthening its legitimacy.
\end{abstract}

Keywords-Government Weibo; Censorship; Governmentality; Management

\section{INTRODUCTION}

Chinese internet censorship has received a great deal of attention in the international media, from Western governments, and from the international human rights community and increasingly from academia. With the increasing importance of Weibo in the daily life of the Chinese people, it is necessary to explore how the Chinese Communist Party specifically responds to and regulates Weibo among other social media. China is not alone in applying what can be seen as a double standard towards the internet, using the technology to promote its economy, while carefully monitoring its use and ultimately retaining tight control over information flows. Even the world's most seemingly democratic nations like the USA or Germany still have limits on what the internet is allowed to do, finding ways to persuade, patrol and police cyberspace (Gerhards \& Schäfer 2010).

The authorities have developed multiple tools for regulating online information, moving beyond the Great Firewall. The Chinese state's disciplinary informationregulating technologies are therefore no longer simply illiberal strategies, such as internet censorship or arrest. Therefore, this paper focuses on the government's efforts to develop new and sophisticated regulatory methods in response to the Weibo era. In the early stages of Weibo, the state took a number of authoritarian measures such as hard censorship to tighten its control of Weibo with the purpose of maintaining strong control over this medium. However, the nature of Weibo's challenges, specifically its instantaneous communication leading to large scale responses, required the government to adopt more sophisticated control measures than ever before. Admitting the power of the internet to bypass political control, the paper shows how the Chinese government has been perceptive in introducing legislative measures and other oversight techniques specifically to regulate Weibo.

\section{EARLY CONVENTIONAL WEIBO REGULATION}

The rise of social media and the widespread dissemination of information through Weibo aroused unexpected management pressures on the Chinese government. In response, the Chinese authorities developed a variety of measures to maintain control, with three types of longstanding censorship of expression identified in Chinese social media (King, Pan \& Robert 2013): The first of these is the previously mentioned Great Firewall, which, while blocking access to information flow into China, did not place new restrictions on the expression of the Chinese people, as they could easily find alternative media platforms through which to express themselves. The second measure to regulate the flow of information on social media was "keyword blocking", which had only very limited effect on freedom of speech as netizens were still able to use other subtle forms of expression such as analogies, metaphors or satire. Beyond the first two barriers to freedom of speech, the third measure involves censors reading and manually removing information that they find objectionable.

Since the arrival of social media, the Chinese government has continued in its efforts to control the medium. Recently the authorities issued a number of severe legal measures to prevent the spreading of irresponsible rumors and to threaten offenders. For example, in August 2013, a well-known online commentator, Charles Xue, was put under administrative detention by Beijing police for alleged involvement in prostitution. With more than 12 million followers on Sina Weibo, Xue, a Chinese-American venture capitalist, admitted that being an internet celebrity had made him feel like an emperor. He admitted to spreading irresponsible internet posts because "the army of supporters who blindly defend me made my vanity expand and I spread some irresponsible information which misled the users" (Xinhua Daily Telegraph 2013). To illustrate his power, he said that a simple post asking for 
donations for a particular cause could draw more than a million yuan (US\$13,000) in less than a week. In addition, Xue had "cooperated" with an environmental expert Liangjie Xia, to spread fabricated information supposedly in the name of science on Weibo, thereby expanding Xia's popular influence on the sale of water purification products.

Arrest has been another typical longstanding form of censorship. For example, on September 17, 2013, a 16-yearold junior school student from Tianshui, in the north-west of China's Gansu Province, was arrested because of a number of his posts on Weibo, generated great debate. The official reasons for the arrest of this student were that he had used Weibo to spread rumors inciting people to disturb the social order, seriously interfering with public security (China News.com 2013). In his posts, the student questioned an unnatural death case in which some facts may have been officially concealed.

Apart from the direct arrest of cyber-dissidents to demonstrate control over the internet, the Chinese government has also waged a "guerrilla war" (Bandurski 2008) against these dissidents. One of its strategies in this war has been the use of China's growing armies of Web commentators, known as the Fifty Cents Party, which involves individuals receiving 50 cents in Chinese currency for each anonymous message they post supporting the government (Shirk 2011).

It is obvious that the primary role of the government in the early stages of Weibo was purely and directly one of regulating information control. Gradually, the state's tactics in managing Weibo have become much softer, so appearing to be more liberal. As the next section illustrates, the government also proactively utilizes and involves itself in Weibo to carry out certain activities that it wants to make public. In order to better communicate with the public, for example, government agencies set up institutional Weibo accounts; therefore, in addition to (but separately from) its authoritarian measures to regulate Weibo, it uses the same forum to apply what appear to be liberalizing strategies to openly communicate with the public.

\section{GOVERNMENT APPLICATION OF WEIBO}

Facing the power of the rebellions seen in the Arab Spring, states including China have still not prohibited the spread of new communication technologies; rather, they have taken a proactive attitude. The rapid development of social media applications (e.g. twitter or microblogs) is helping the US and Canadian governments to better communicate with their peers and citizens, positing Government 2.0 as the new shape of government (Eggers 2007). China is no exception. Alongside these evolving state measures to exercise greater control over social media content, there has also been increasing evidence that the internet can also be a powerful tool to accomplish the government's own goals - a tool that the state can employ in its ongoing public relations efforts, which knowing cyber analysts at the China Media Project have dubbed the "Control 2.0" mode of keeping order online (Bandurski 2008). The Chinese party-state has currently made every effort to integrate Weibo into its new public management strategy (Noesselt 2013).
Social media tools have been increasingly adopted by the government for various purposes, for example, governments harness new technologies to enhance information exchange with citizens, while local governments in America use different kinds of social media to communicate with residents to support better preparation for emergencies. Police departments use Weibo to share information with their peer departments and to communicate with netizens to acquire clues to break cases and in response to emergencies (Eggers 2007). This method is also adopted by the Chinese government, with an increasing number of government agencies and officials opening Weibo accounts to allow a channel for interacting with citizens. Government Weibo accounts have been registered by officials and departments to deal with a wide range of matters, such as public security, publicity, justice, education and sports. Among the various government agencies, police departments from various levels have emerged as the most active players in opening Weibo accounts.

Since the launch of government Weibo in China, it has played an increasingly important role in the field of providing information in emergencies, setting public issues, gathering social resources and generating public opinion. The year 2011 was labeled "the year of government Weibo in China", with "microblogging politics" becoming a popular trend. The rise of government Weibo has helped to improve the responsiveness and transparency of governance. Because of its efficiency and improved service, some officials' influence has been greatly improved. In the meanwhile, the Chinese authorities are willing to use government Weibo as a watchdog to monitor the officials' behaviors at different levels, particularly at the local level. An awareness of the importance of Weibo in information dissemination and its widespread influence has seen many Chinese authorities open Weibo accounts for their own purposes.

The Chinese government has changed its tactics to make good use of the platform to achieve maximum influence. The government is always seeking more effective uses of this platform. It increases its use of the site as an arena in which to communicate with the public because it benefits both Chinese society and its people by promoting transparency within the government. Traditionally, the Chinese government treats the media as its 'throat and tongue'; similarly, the government has taken the same attitude to Weibo. It has been highlighted in the report that the "Weibo national team" has risen since 2012, with the "mouths and throats" of the Xinhua News Agency, People's Daily, CCTV and other central media constantly opening Weibo accounts and trying to dominate the "micro discourse" of Weibo (Tang et al. 2013). In scrutinizing the use of Weibo by government officials and departments, it appears that the government's goal in using Weibo in this way is twofold, not only to make the governing process more convenient, but to emphasize the government's commitment to build a more effective bureaucracy and a more transparent government.

Additionally, certain internet incidents have shown that online exposure of social issues by Weibo users can lead to the government reversing decisions, with officials occasionally even arrested and charged with corruption. At this point, the 
government has the same goal as the citizens. The purpose is to help the government to realize its goal of becoming a transparent government within the framework of what is helpful for government control and political stability. In 2013, in terms of quality, it was expected that government Weibo would expand further into new areas such as industry and administration, to expand the government's provision of information and to strengthen the social management of innovation, the state are in accord.

\section{A. Government Weibo to Improve Transparency}

The use of government Weibo has a number of purposes, and one of the primary purposes is to improve transparency. During the huge transition of the Chinese socio-economic change, notable social disparities have emerged; therefore, social stability and public safety are highly emphasized in China. During the early era of e-government, some scholars doubted the potential and progress of China's e-government to 'serve the people' (Zhang 2002). In the current Weibo era, the Chinese government has in fact progressed significantly in better serving the people by openly recognizing the importance of online public opinion. In June 2010, it issued a white paper on the internet in China, stating that the authorities attach great importance to social conditions and public opinion as reflected on the internet, which has become a bridge facilitating direct communication between the government and the public.

The effectiveness of this commitment to two-way communications between government and the public has been strongly reflected on the Weibo sites of local governments. The government's emphasis on the state's agenda-setting role is true to the original e-government project, which declared agenda-setting as its most important role (Zhang 2002). On August 22, 2013, the so-called "trial of the century" of the former top politician, Bo Xilai, was carried out by the Intermediate People's Court in Jinan, in eastern China's Shandong province. Bo was charged with bribery, embezzlement and the abuse of power. While trials of Party officials have usually been held in secrecy, these trial proceedings, remarkably, were broadcast live online on Sina Weibo, for the first time in Chinese legal history. Despite certain critiques that the "real-time" Weibo broadcast was actually selective and not genuinely real-time, it is nevertheless noted by China's official media outlet, the People's Daily, as an example of "historical transparency and of the openness of China's rule of law" (Zhang 2013). This five-day trial attracted more than 590,000 followers on Weibo, and it is extolled as a significant benchmark for social media's role in increasing transparency in the Chinese justice system, at least when it comes the trials of Party officials (ibid).

In the process, Weibo broke down the previous bureaucratic modes of communication, and it was helpful for the government to gather public opinion in response to the trial. Central government takes overall responsibility and oversight for social stability and political legitimacy on the international stage, serving to monitor and curb local government behaviors. Therefore, Weibo is a forum of "transparent technology", which creates new possibilities for exposing and challenging the abuse of power, and for monitoring the abuse of power. The use of Weibo in this way also offered a means of simultaneously prioritizing while limiting and defining the message and the policy behind it. This tactical use of technology by the Chinese government, of co-opting a public communications space, is a remarkable example of governmentality, as conceptualized by Foucault. The Weibo broadcast becomes a tactic of governing, designed to shape the hearts and minds of the Chinese to conform to desired cultural and political molds (Dean 1999). It embodies the notion of governmentality, defined as "the calculated direction of human conduct and behaviour" (ibid, p.2).

According to the statistics noted earlier, approximately half of the activated government Weibo sites are launched by police departments, which steadily account for the top ten prestigious government Weibo sites. The launch of police Weibo may contribute significantly to sharing information with their peer departments, enabling the government to rebuild its social image and retrieve and consolidate public trust during emergencies. For example, in releasing and exchanging information with peer departments and citizens it assists the police to acquire clues that can resolve cases, and it helps to solve long-standing social problems such as saving abducted children.

\section{B. Fighting Corruption in order to Improve Its Image}

Weibo can also help the government to weed out corruption and to produce more sophisticated propaganda. Preventing corruption strengthens the government's legitimacy, while smarter propaganda is able to improve the government's image. Some scholars have noted that the central government actually allows ordinary people to expose the corruption of ordinary officials (China.org.cn 2013), because the moderate governance of corruption can help to restore the deteriorating image of the Party and to maintain social stability, which is consistent with government interests. In this way, providing a further example of public online scrutiny of a group previously protected, Weibo has been used to bring corrupt government officials to account. Zhou Jiugeng, the director of Nanjing's property bureau, was fired after pictures of him appeared on the internet in 2008 wearing an expensive Vacheron Constantin watch, a luxury purchase assumed to be beyond his salary. On August 26, 2012, the wrong doings of Yang Dacai — an official in Shaanxi province appeared online. His behaviour sparked an outcry when pictures posted on Weibo showed him smiling while visiting a traffic accident site where 36 people had died. This was followed by images showing that he was also wearing a luxurious watch that critics considered he would not have been able to afford on his salary. Chinese internet users discussed his alleged corruption on Weibo and other online forums, requesting the local government dismiss Mr Yang, after which, he was indeed sacked by provincial officials for serious wrongdoing.

In 2013, a crash on one of China's new high-speed rail lines killed more than 40 people. The news was broken on Weibo by an eyewitness, which was followed by a furious online reaction to the government's handling of the crisis. Senior railway ministry officials resigned, and the then Prime Minister, Wen Jiabao, made a public apology. As this case 
embodies, the exposure of corruption on Weibo is an important element in this analysis, with a number of local officials having been forced to resign after being exposed on line. At the same time it illustrates how the central government can reassert its control over the governing authorities, which includes improving the quality of surveillance and the commitment to the elimination of corruption. It therefore illustrates a transformation in governance. The new technologies are powerful instruments for increasing transparency and accountability. In examples of new media events such as the 2013 train crash, a triangular relationship between media, citizens and government creates a new kind of power allocation mechanism. Such events ultimately transited from the new media platform to seize the avid attention of the traditional media. Hence, after such a fermentation period, it could be responsible for the formation of strong public opinion pressuring the government and urging officials to resolve problems immediately. Such a triangulation, from online witness-based media exposure to traditional media to government, could become a new path for the state's governance model.

The Chinese government is not naturally the opponent of internet incidents, sometimes it tacitly favors them. Morozov (2011) argues that occasionally, online campaigns succeed precisely because the government sees the aims of such campaigns as being in line with the government's plans. Thus the Chinese state intends to take advantage of the power of the internet both to implement its politics and to prolong its rule. On some occasions the government and the citizens share the same interests and goals, such as in cases of online nationalism or anti-corruption efforts. Online activism and the government are not always in opposition, when society and the state are in accord.

\section{Civic Uses of Government Weibo for Publicizing Information}

The proliferation of government Weibo marks another stage in the progress of China's e-government project, although it does not, as some suggest, mark any major or radical shift in the party-state's internet strategy (Noesselt 2013). The adoption of Weibo by governments could indeed be considered a straightforward approach as a form of technology for better governance. While many studies show concern over the application of new media technologies as part of e-government, this paper probes the adoption of Weibo by the Chinese government as marking a change in the state's regulatory methods. The background to this change is the tremendous socio-economic transformation from a central planned economy to a market-oriented economy from the late 1970 s, which has greatly changed the philosophy and operation of the government.

The government websites are certainly used to provide basic information or to offer online services, but the emergence of Weibo, enabling government officials to gradually open Weibo accounts, has changed its previous style of interaction. The term "technologies" suggests a particular approach to the analysis of the activity of government interaction with and using Weibo in China. The primary factor here is to minimize the risk of weakening existing political control, while engagingly publicly online. On one level, as described earlier, government employs the internet to varying transparent ends. For example, police make use of Weibo to catch murderers in China.

With authoritarianism deeply-rooted in its polity, China lacks reliable mechanisms to take the public pulse on key issues. It must turn to the internet for help, where it is much easier to detect and gauge public opinion. On some occasions the online discourse of 'mass incidents' appearing on Weibo can reinforce government legitimacy.

\section{FORMS OF INFORMATION MANAGEMENT}

The previously discussed Bo Xilai trial represents the new relationship between the Chinese government and Weibo, in co-opting the media platform to demonstrate its transparency and commitment to root out corruption, while using the platform to achieve a sophisticated political purpose. The Chinese government has therefore preemptively taken advantage of the new media to set the agenda ahead. In other words, instead of the traditional passive response to online protests, the Chinese government has learned to seize the initiative in the battle with the citizens. The government uses social media not only to publicize Party principles, a traditional approach; a new level of government control emerges when the government defines this use of social media as a healthy internet culture. By implication then, what the government does not consider a healthy internet culture is dangerous to the participants. The government therefore expects users of social media to decide what a healthy internet culture is and to stay within those boundaries. This means the government adopts a strategy of personalizing mind control in a completely new way.

At the same time, the government regularly issues regulations to tighten the government's grip on the internet while successfully transferring the responsibility to the users. These types of internet regulation are a kind of illiberal governmentality - where internet and social media users are directed into making preferred statements and choices via the legislative codes. These legal codes and policies are employed by regulatory authorities to "shape, normalize and instrumentals the conduct, thought, decisions and aspirations of others" (Miller \& Rose 1990, p.82). Several examples have emerged in the last few years. With the rise of internet celebrities, China issued seven bottom lines to promote social responsibility among microbloggers and to regulate online codes of conduct, namely that they would monitor:

\section{Laws and regulations;}

2. Socialist system;

\section{State interests;}

4. Citizen's legal rights;

5. Social and public order;

6. Morality;

7. Truth of information.

As Rosen (2010, p.510) argues, despite government control, internet users still "find ways to circumvent and 
subvert government restrictions". Chinese internet users have evolved sophisticated forms of political expression, including political satire and criticism of the state, without facing harsh repression. As Yang (2009, p.49) argues, in the evolution of the Chinese internet-control regime, government control strategies have recently become more proactive, and multilayered and governmentalised. In this new game, social media users adopt new rules in the new game. For example, they use different methods to bypass control. The widely seen cartoon creature called the "grass mud horse" (the name in Chinese is homonym for an expletive) as a way of protest. The word "river crabs" sounds very similar to the word of $\mathrm{Hu}$ Jintao's political philosophy harmony (hexie). This smart use of word play "has become an icon of resistance to censorship" and this form of subversive expression and cartoon videos may seem a juvenile response to unreasonable rule" (see Diamond 2010, p.74). As Yang (2009) notes, "online communities with strong collective sentiments...can generate effective offline action" (pp.180-181), and "although democracy as a political system remains an ideal and not a reality, at the grassroots level, people are already practicing and experimenting with forms of citizen democracy" (pp.220221). The decentralized nature of the internet has the potential for the netizens to resist in a "safer" environment. Throughout his book, Yang (2009) shows how individuals have used a number of strategies to circumvent censorship and to play in a "world of carnival, community and contention" (ibid, p.1). These strategies include a full range of satire, irony and parody against the state.

\section{CONCLUSION}

The transformation of China's political system from the highly integrated and all-inclusive state to the empowering of local government authorities has significant implications for the understanding of information control and regulation of China's Weibo. Although the long-term effect of internet regulation remains to be seen on Weibo, ranging from technical restrictions of filtering to demanding that the internet service providers monitor content, to arresting individuals who violate the law, the ever-evolving information technologies make it possible for the authorities to keep pace with the varying tactics of Weibo users. This has been the case from the passive responses in the past to actively taking initiatives in the present. Both government and Weibo users continue to evolve their strategies to match one another.

In summary, the government implements different strategies for different content on Weibo. Weibo autonomy has not, however, emerged in its place. Rather, a new mode of state control has taken shape on Weibo. The key feature of this control is that the state controls Weibo flexibly, selectively and proactively, in a subtle way. It will apply direct and intensive control when it feels necessary and use subtle and invisible control when it feels other methods are unnecessary.

\section{REFERENCES}

[1] Bandurski, D 2008, 'China's guerrilla war for the Web', Far Eastern Economic Review, 15 July, viewed 20 April 2017, <http://samgeall.com/post/42314921/far-eastern-economic-reviewchinas-guerrilla-war-for>.

[2] China News.com 2013, 'Lvshi: bei xingju chuzhongsheng yanlun he qunzhong youxing wu yinguo guanxi (Lawyer: Speech of the arrested junior student has no cause effect with mass demostration)', China News.com, 22 September, viewed 20 October 2013, <http://www.chinanews.com/fz/2013/09-22/5304163.shtml>.

[3] China.org.cn 2013, 'Weibo: an eye on corruption', China.org.cn, March 11, viewed on May 2018, <http://www.china.org.cn/china/NPC_CPPCC_2013/201303/11/content_28201650.htm>.

[4] Dean, M 1999, Governmentality: power and rule in modern society, Sage, London.

[5] Diamond, L 2010, 'Liberation technology', Journal of Democracy, vol. 21, no. 3, pp. 69-83.

[6] Eggers, WD 2007, Government 2.0: using technology to improve education, cut red tape, reduce gridlock and enhance democracy, Rowman \& Littlefield Publishers, Lanham.

[7] Gerhards, J \& Schäfer, MS 2010, 'Is the internet a better public sphere? comparing old and new media in the USA and Germany', New Media \& Society, vol. 12, no. 1, pp.143-160.

[8] King, G, Pan, J \& Roberts, M 2013, 'How censorship in China allows government criticism but silences collective expression', American Political Science Review, vol. 107, no. 2, pp. 326-34.

[9] Miller, P \& Rose, N 1990, 'Political rationalities and technologies of government', in Hanninen, $\mathrm{S}$ and Palonen, K (eds.), Texts, Contexts, Concepts: Studies in Politics and Power in Language, Finnish political Science Association, Helsinki, pp.171-183.

[10] Morozov, E 2011, The net delusion: the dark side of internet freedom, Public Affairs, New York.

[11] Noesselt, N 2013, 'Microblogs and the adaptation of the Chinese partystate's governance Strategy', Governance, vol. 27, no. 3, pp.449-468.

[12] Rosen, S 2010, 'Is the internet a positive force in the development of civil society, a public sphere and democratization in China?', International Journal of Communication, vol. 4, pp. 509-516.

[13] Shirk, S 2011, 'Changing media, changing China', in Shirk, S (ed.), Changing Media, Changing China, Oxford University Press, New York, pp. 1-37.

[14] Tang, X, Wu, X, Huang, C \& Liu, R (eds.) 2013, Annual report on development of new media in China 2013, China Social Sciences Academic Press, Beijing.

[15] Xinhua Daily Telegraph 2013, 'Daishoukao de 'xuemanzi' tan 'da V' xinlu (Charles Xue with handcuff talks about 'big V')', 16 September, viewed 20 January 2014, <http://news.xinhuanet.com/mrdx/201309/16/c_132722998.htm>.

[16] Yang, G 2009, The Power of the internet in China: citizen activism online, Columbia University Press, New York.

[17] Zhang, J 2002, "Will the government "serve the people"? the development of Chinese e-government', New Media \& Society, vol. 4, no. 2, pp. 163-184.

[18] Zhang, Y 2013, 'Fall of a princeling: Bo Xilai's trial by Chinese social media', The Conversation, 30 August, viewed 20 March 2014, <http://theconversation.com/fall-of-a-princeling-bo-xilais-trial-bychinese-social-media-17599>. 